Editorial

\section{Brown fat tissue: Therapeutic potential for insulin resistance, new hopes for tomorrow}

\author{
Arefhosseini Seyedrafie and Alijani Sepideh* \\ Department of Biochemistry and Diet Therapy, Faculty of Nutrition and Food Sciences, Tabriz \\ University of Medical Sciences, Iran
}

The well recognized white adipose tissue is an endocrinal organ secreting various hormones and this article simply indicates to the physiologic concepts brown fat tissues (BAT) which are extremely active endocrine organs and play various metabolic active roles in intermediate metabolism. The physiologic function of Brown adipose tissues contributes to energy-producing parts of the cell. Its amount is rare up to approximately one hundred and thirty gram and implies important characteristics for mammals. An increase in energy expenditure could be an aim by activation of BAT, seems futurity to reduce body weight that needs a vast majority of fundamental research to facilitate its occurrence [1]. Brown fat tissue generates heat and has valuable importance for human metabolism [2,3]. Brown fat tissue is decreased in overweight and obese people and possibly activating brown fat tissue might help for reducing weight and weight-related metabolic disorders like insulin resistance.

Histologically, there are three major types of adipose tissue: white adipose tissue (WAT), ( than 95\% of adipose mass); brown adipose tissue (BAT), (1\% to $2 \%$ ) existing in the cervical, axillary, and paraspinal regions; and beige/brite adipose tissue, which is cells interspersed within WAT that are capable of transforming into brown-like adipocytes following cold exposure or adrenergic stimulation [4].

The transition from underweight to overweight and obesity has happened in most of the countries around the world and this circumstance with obesity during childhood leads to life treating disease in adulthood [5]. Eighty percent of diabetic patients are classified as overweight or obese and \%30 of obese children under the age of 12 show insulin resistance [6]. This means many active society members are supposed to start metabolic syndrome throughout their lifetime. Considering various metabolic reactions and their following functions and finally, their consequent produced results ,and challenges of accepting old dietary recommendations as a safe one with no metabolic hazard that introduced simple

\section{More Information}

*Address for Correspondence: Sepideh Alijani, Department of Biochemistry and Diet Therapy, Faculty of Nutrition and Food Sciences, Tabriz University of Medical Sciences, Iran, Tel: +989372552882;

Email: spd.alijani@gmail.com

Submitted: November 06, 2020

Approved: December 12, 2020

Published: December 14, 2020

How to cite this article: Seyedrafie A, Sepideh A. Brown fat tissue: Therapeutic potentia for insulin resistance, new hopes for tomorrow. New Insights Obes Gene Beyond. 2020; 4: 022-023

DOI: 10.29328/journal.niogb.1001014

ORCiD: orcid.org/0000-0003-2583-1663

Copyright: @ 2020 Seyedrafie A, et al. This is an open access article distributed under the Creative Commons Attribution License, which permits unrestricted use, distribution, and reproduction in any medium, provided the original work is properly cited.

Keywords: BAT; Adipose tissue; Insulin resistance; Brown fat tissue

A) Check for updates

(1) OPEn ACCEss

sugar as the main reason of common metabolic disorders like metabolic syndrome are the pivotal reasons for preparing this [7]. Particularly, adipose tissue as a compartment of the living organism is specialized for storing triglyceride that is gathered in a single large and droplet of triglyceride and surrounded by a peril pin to keep it stable in adipocyte [8].

BAT is reduced in most overweight and obese subjects. Brown adipose tissue may be metabolically important in men, and in fact, its reduction in most overweight or obese subjects may make it a target for the treatment of obesity. The brownadipose-tissue activity is significantly lower in overweight or obese males than in lean male subjects [9]. As a conclusive result from new researches about the contribution of BAT in human metabolism, it may enable new strategies to prevent excess body fat accumulation or fatness. Clear relationships (negative relationship) between BAT and obesity rates have been shown.

It achieves a very vast research field for the contribution of this active parameter to combat the present largest problem of health in the developing and developed world.

It is also now recognized that insulin resistance may be the common link between obesity, impaired glucose tolerance or 
type 2 diabetes, dyslipidemia (high LDL cholesterol, low HDL cholesterol, and high TAG concentrations), hypertension, and impaired fibrinolysis which together has been called metabolic syndrome or syndrome X [10]. Diet has an important role to play in the prevention of CHD, type 2 diabetes, metabolic syndrome, and insulin resistance [11-14]. BAT should be aimed at future metabolic studies as a new way to find out the solution for human society's problem. A new way to enable the next strategies to prevent excess body fat accumulation in man is a desirable wish to beat the problem of the world which is overweight and obesity. Higher BAT volume and activity improve glycemic control and insulin sensitivity [15]. $ß$-adrenoceptor-UCP1 system regulates BAT in experimental animals like rodents [16]. Recent studies have indicated that the loss of p85 $\alpha$ in BAT enhances its thermogenic functionality, high-fat diet-induced adiposity and body weight, insulin resistance, and liver steatosis [17]. BAT transplantation have shown improvements in glucose metabolism, insulin sensitivity reductions in body mass in recipients. These effects may occur through different mechanisms, such as releasing batokines [18]. Some researchers also suggest that the gut microbiota modulates both browning of white adipose tissue and the activity of brown adipose tissue [19]. Acetate increases the activity of brown fat [19]. The possible effects of bio-molecules with ameliorating or accelerating effects, besides the medications, create a big hope for supplementary effects by BAT. It is a golden aim that instead of using different weight reduction methods the applications for brown adipose tissue activations, BAT transplantation or browning methods of WAT would be used.

\section{References}

1. Cypess AM,HaftCR, LaughlinMR,HuHH.Brownfatinhumans:consensus points and experimental guidelines. Cell Metab. 2014; 20: 408-415. PubMed: https://pubmed.ncbi.nlm.nih.gov/25185947/

2. Saely $\mathrm{CH}$, Geiger K, Drexel HJG. Brown versus white adipose tissue: a mini-review. Gerontology. 2012; 58: 15-23.

PubMed: https://pubmed.ncbi.nlm.nih.gov/21135534/

3. Contreras C, Gonzalez F, Fernø J, Diéguez C, Rahmouni K, et al. The brain and brown fat. Ann Med. 2015; 47: 150-168.

PubMed: https://pubmed.ncbi.nlm.nih.gov/24915455/

4. Kahn CR, Wang G, Lee KY. Altered adipose tissue and adipocyte function in the pathogenesis of metabolic syndrome. J Clin Invest. 2019; 129: 3990-4000.

PubMed: https://pubmed.ncbi.nlm.nih.gov/31573548/

5. Lancet NRFCJT. Trends in adult body-mass index in 200 countries from 1975 to 2014: a pooled analysis of 1698 population-based measurement studies with 19. 2 million participants. Lancet. 2016; 387: 1377-1396. PubMed: https://pubmed.ncbi.nlm.nih.gov/27115820/
6. Kennedy A, Martinez K, Chuang CC, LaPoint K, Mclntosh M. Saturated fatty acid-mediated inflammation and insulin resistance in adipose tissue: mechanisms of action and implications. J Nutr. 2009; 139: 1-4. PubMed: https://pubmed.ncbi.nlm.nih.gov/19056664/

7. Arefhosseini S, Edwards C, Malkova D, Higgins S, metabolism. Effect of advice to increase carbohydrate and reduce fat intake on dietary profile and plasma lipid concentrations in healthy postmenopausal women. Ann Nutr Metab. 2009; 54: 138-144.

PubMed: https://pubmed.ncbi.nlm.nih.gov/19339775/

8. Deng $Y$, Scherer PE. Adipokines as novel biomarkers and regulators of the metabolic syndrome. Ann N Y Acad Sci. 2010; 1212: E1. PubMed: https://pubmed.ncbi.nlm.nih.gov/21276002/

9. van Marken Lichtenbelt WD, Schrauwen P. Implications of nonshivering thermogenesis for energy balance regulation in humans. J Physiol Regul Integr Comp Physiol. 2011; 301: R285-R96.

PubMed: https://pubmed.ncbi.nlm.nih.gov/21490370/

10. Reaven GM, Lithell H, Landsberg L. Hypertension and associated metabolic abnormalities - the role of insulin resistance and the sympathoadrenal system. N Engl J Med. 1996; 334: 374-382. PubMed: https://pubmed.ncbi.nlm.nih.gov/8538710/

11. Joshipura KJ, Hu FB, Manson JE, Stampfer MJ, Rimm EB, et al. The effect of fruit and vegetable intake on risk for coronary heart disease. Ann Intern Med. 2001; 134: 1106-1114.

PubMed: https://pubmed.ncbi.nlm.nih.gov/11412050/

12. Hu FB, Manson JE, Stampfer MJ, Colditz GA, Liu S, et al. Diet, lifestyle, and the risk of type 2 diabetes mellitus in women. $\mathrm{N}$ Engl J Med. 2001b; 345: 790-797.

PubMed: https://pubmed.ncbi.nlm.nih.gov/11556298/

13. Fung TT, Willett WC, Stampfer MJ, Manson JE, Hu FB. Dietary patterns and the risk of coronary heart disease in women. Arch Intern Med. 2001; 161: 1857-1862.

PubMed: https://pubmed.ncbi.nlm.nih.gov/11493127/

14. Poulter N. Global risk of cardiovascular disease. Heart. 2003; 89: ii2-5. PubMed: https://pubmed.ncbi.nlm.nih.gov/12695425/

15. Chondronikola $M$. The role of brown adipose tissue and the thermogenic adipocytes in glucose metabolism: recent advances and open questions. Curr Opin Clin Nutr Metab Care. 2020; 23: 282-287. PubMed: https://pubmed.ncbi.nlm.nih.gov/32412979/

16. Wang Q, Zhang M, Ning G, Gu W, Su T, et al. Brown adipose tissue in humans is activated by elevated plasma catecholamines levels and is inversely related to central obesity. PLoS One. 2011; 6: e21006. PubMed: https://pubmed.ncbi.nlm.nih.gov/21701596/

17. Gomez-Hernandez A, Lopez-Pastor AR, Rubio-Longas C, Majewski P, Beneit N, et al. Specific knockout of p85a in brown adipose tissue induces resistance to high-fat diet-induced obesity and its metabolic complications in male mice. Mol Metab. 2020; 31: 1-13.

PubMed: https://pubmed.ncbi.nlm.nih.gov/31918912/

18. White JD, Dewal RS, Stanford KI. The beneficial effects of brown adipose tissue transplantation. Mol Aspects Med. 2019; 68: 74-81. PubMed: https://pubmed.ncbi.nlm.nih.gov/31228478/

19. Moreno-Navarrete JM, Fernandez-Real JM. The gut microbiota modulates both browning of white adipose tissue and the activity of brown adipose tissue. Rev Endocr Metab Disord. 2019; 20: 387-397. PubMed: https://pubmed.ncbi.nlm.nih.gov/31776853/ 